\title{
Planetary health and reduction in meat consumption
}

\author{
Dora Marinova ${ }^{*}$ and Diana Bogueva
}

\begin{abstract}
Background: With an annual meat consumption of $110 \mathrm{~kg}$ per capita, Australia is one of the top countries in the world according to this indicator. High meat consumption however is associated with adverse impacts on the planet's ecological systems and also has potential undesirable impacts on human health due mainly to cancer risk. Despite scientific evidence about the negative connection between the consumption of animal-based products and planetary health, people continue to adhere to meat-rich diets. Based on a 2018 survey of residents in Sydney, Australia, this paper explores meat consumption and its influence on planetary health by investigating issues related to frequency, reasons, impacts and planned dietary changes.

Results: The survey reveals lack of general awareness about the negative implications to human wellbeing and the health of the natural environment of high meat consumption. Only 10\% of the Sydney residents report to be currently adhering to a predominantly plant-based diet. A large fraction of the respondents (42\%) see meat as a healthy and nutritious choice contrary to recent dietary guidelines. Meat is further associated with strength (19\% of the respondents) as well as culture and family traditions (18\%). Only 29\% of the participants are aware of livestock's negative impacts on planetary health and even within this group, a large fraction (88\%) continues to consume meat. Although there are signs of dietary changes towards more plant-based options, their extent is not big enough to significantly transform the current trends and prevent further negative impacts from people's preference for meat.

Conclusions: An argument is put forward for social marketing interventions to influence people's dietary behaviour. In addition to building awareness about the negative consequences on planetary health from high consumption of animal-based foods, popularising the achievements of vegan athletes can help dispel existing myths about the link between meat and strength. A new dietary culture which endorses plant-based foods is required for the Anthropocene to arrest existential threats related to climate change, the use of land and other resources, and help shift Australians' preferences away from high meat consumption. This will contribute to better nutrition, food security and achievement of global sustainable development goals.
\end{abstract}

Keywords: Sustainability, Meat consumption, Food, Sydney, Australia, Planetary health, Human health, Ecological systems, Climate change, Diet

\section{Introduction}

Australians are a nation of meat-eaters. Although the 2016 Roy Morgan poll shows a steady increase in the number of Australian adults who self-identify as adhering to a predominantly vegetarian diet, their share remains low at $9.7 \%$ (up from $9.5 \%$ in 2015) [1]. There is yet no other recent reliable data to estimate the number of vegetarians in Australia, however, according to official statistics Australians continue to have one of the highest

\footnotetext{
* Correspondence: d.marinova@curtin.edu.au

Curtin University Sustainability Policy (CUSP) Institute, GPO Box U1987, Perth, WA 6845, Australia
}

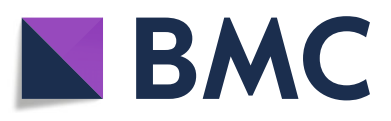

(c) The Author(s). 2019 Open Access This article is distributed under the terms of the Creative Commons Attribution 4.0 International License (http://creativecommons.org/licenses/by/4.0/), which permits unrestricted use, distribution, and

reproduction in any medium, provided you give appropriate credit to the original author(s) and the source, provide a link to the Creative Commons license, and indicate if changes were made. The Creative Commons Public Domain Dedication waiver (http://creativecommons.org/publicdomain/zero/1.0/) applies to the data made available in this article, unless otherwise stated. per capita meat consumption in the world - around 110 $\mathrm{kg}$ per person per annum [2]. In fact, data from to the United Nations' Food and Agriculture Organisation (FAO) show Australia's per capita meat supply to be the highest in the world [3] followed closely by the United States of America (USA).

Our food preferences however are dynamic and many wealthy economies, such as Australia, Canada and the European Union have witnessed a decrease in beef consumption replaced by higher levels of chicken intake [4]. Some even refer to "peak beef" - that is, achieving a maximum level of individual beef consumption in 
developed countries, which is followed by a gradual decrease and increased preferences for other food [4]. In Australia "peak beef" was achieved around 2004, however, meat consumption did not drop after that as there was a marked increase in the supply of chicken and pork [5].

Irrespective as to whether we opt for beef, chicken or pork, animal-based food products have a higher ecological footprint than plant alternatives. Fruits, vegetables, legumes, roots, nuts and other plant-based foods are also better from a human health perspective $[6,7]$. In other words, a reduction in the dependence of human diets on animal-based products is beneficial for the health of both, the planet and its human inhabitants - a synergy described as co-benefits, that is simultaneous benefits or a win-win situation.

In recent years the fundamental link between the health of the ecological environment and human wellbeing is becoming recognised as part of the concept of planetary health [8]. Almost all sustainability-oriented behavioural and technological changes, such as renewable energy and sustainable transport, generate co-benefits for planetary health. Reduction in the consumption of animal-based products, however, is the one which has the deepest and most immediate impact on planetary health. It is no longer possible to ignore the link between the consumption of animal products, and specifically meat, and planetary health. Whilst there is ample scientific evidence about the need to cut meat consumption in order to restore and maintain the health of the planet's ecological systems, arrest land conversion for raising and feeding livestock and prevent further biodiversity loss, many policy makers and the broader public are finding it difficult to acknowledge the necessity to change people's diets. With abundance of food choices, western nations appear to be obsessed with meat consumption. This leads to deteriorating planetary health putting at risk future generations. The sooner meat consumption is curbed, the better. However, do we know how to make people eat less meat? Are people even aware of the inverse link between meat consumption and planetary health in order for them to consider changing their dietary habits?

Using 2018 data from a survey in Sydney, Australia, this paper embarks on the task to reveal possible answers to these questions. It is surprising that people who can afford to make a switch in their diets away from meat are reluctant to do this which indicates an urgent need to influence their behaviour. We refer to the need for social marketing as a form of educating and spreading the message that the quickest intervention to improve planetary health is reduction in meat consumption. The concept of planetary health is explained first, including why meat consumption plays such a crucial role. This is followed by a discussion of the Sydney survey results and some policy options to promote reduction in meat consumption.

\section{Planetary health}

At the start of 2014, The Lancet - the world's most prestigious medical journal, published a manifesto for planetary health [8] which was signed by 7390 scientists across the globe predominantly from the fields of medicine, public health, health care, ecology and environmental science. In 2017, The Lancet declared planetary health as a new research area on its own right requiring multidisciplinary, interdisciplinary and transdisciplinary efforts to deal with unprecedented challenges. This relatively new integrating concept focusses on safeguarding "the health of human civilisation and the state of the natural systems on which it depends" [9] [p.1978] and is attracting wider support, including from reputable funding and charitable bodies, such as the Rockefeller Foundation. It essentially represents the reality that we cannot maintain good levels of human health when the ecological systems which support life on earth are in a poor or unsatisfactory state. Horton et al. [8] describe planetary health also as a social movement which aims to transform current practices of living and doing business at all levels - individual, societal, national, regional and global, in order to respond to the threats to human wellbeing, the sustainability of the human civilisation and the health of the planet we inhabit and share with so many other species. Food, being at the core of human existence, is the issue which requires the most immediate attention in this social movement for restoring and preserving planetary health.

The establishment of the planetary health conceptual research area coincides with the adoption by the United Nations (UN) of a global sustainability agenda through the 17 Sustainable Development Goals (SDGs) [10]. These goals aim at eradicating hunger and poverty, providing a good quality of life and meaningful opportunities for people across the globe but also at protecting the planet from further threats of biological annihilation. According to Horton and Lo [11], planetary health puts people at the centre of all current problems. People are at the core of the Anthropocene [12, 13] - the current geological time period during which the Earth's complex systems are being drastically transformed because of human activities. This includes climate change, loss of biodiversity, ocean acidification, sea level rise, air, water and soil pollution as well as many other socio-technological transformation processes, such as new food production technologies, use of land and natural resources, including phosphorus, demographic trends, cultural and ideological shifts, zoonotic disease spread, pandemics, military and civil conflicts. Many thinkers have drawn attention to human impact on the planet. Vernadsky wrote in the 1920s that people are in a position to 
re-shape the planet and have as strong an impact as any geological and physical forces $[14,15]$. In the 1970s, Meadow et al. drew attention to the limits of the planet and the threats the constant pursuit of economic growth poses [16]. Twenty years later, Fugelli observed that the planet is becoming sick with global environmental disruptions having potentially serious negative consequences for human health [17]. The 2015 UN SDGs represent a unified effort to counteract these warning signs and put the responsibility on people to change the course of events through collective actions [18].

Sustainable Development Goal 2 "No Hunger" directly relates to food security and elimination of malnutrition. Food is a very complex area with many poorly understood socio-ecological processes in action at the population-consumption-environment nexus which are often described as "the tragedy of the commons" [19]. They relate to inefficiency in the allocation of resources between countries and across time as well as to contingencies, calamities, unintended consequences and unforeseen events, such as droughts, floods, contaminations, invasive species and diseases. Many analyses show that the marketplace, particularly the global marketplace, cannot correct for such inefficiencies and externalities which implies that only collective actions can contravene to redress the situation [19]. For example, wealthy countries have higher economic power on the global market for grains which leads to inefficient use of valuable resources as animal feed rather than directly for human consumption [20]. Hence, the global commons, which include land, water, vegetation and minerals, are being exploited through a longer nutritionally inefficient plant-to animal-to human (instead of plant-to human) chains for the benefits of a much smaller fraction of the population triggering concerns about world hunger whilst generating obesity problems in wealthier societies. The 2018 country profile of Australia shows poor levels of performance for many sustainability indicators, including SDG 2 because of high prevalence of obesity and unsatisfactory management of nitrogen related to agricultural practices [21].

It is not enough for planetary health to register environmental deterioration because of human actions, it goes deeper into the problems causing such destruction. If left poorly understood and unattended, these problems which now may sound to some as doom and gloom, will become strong factors causing the health of the planet and of humanity to get worse. Food consumers in Australia and other wealthy parts of the world are "mortgaging the health of future generations to realise economic and development gains in the present" [22]. It is not clear though how much of this damage is caused because of lack of awareness among the general public.
Research on the other hand, continues to produce mounting evidence about global warming being human-induced [23, 24] with livestock contributing a significant share of the global greenhouse gas emissions. The global warming potential of agriculture estimated on a 20-year timescale (rather than the commonly used 100-year timescale estimates which spread the impact of methane over a period 4-5 times longer than its physical existence in the earth's atmosphere) is assessed to be the highest of any other economic sector, namely $22 \%$ compared to $20 \%$ for industry, $17 \%$ for electricity and heat production, and $17 \%$ for other energy (such as petroleum refining, coke ovens, briquettes, blast furnaces for pig iron production etc.) [25]. Livestock is contributing at least $80 \%$ of the agricultural emissions. In Australia, replacing beef with a plant-based option such as wheat generates 113 times less greenhouse gas emissions per nutrient [26]. Many other investigations produce similar findings. A meta-analysis of 570 studies from 119 countries examining the life-cycle environmental footprints of 40 different food items which provide $90 \%$ of the global protein and calorie intake, shows that beef is the option with the highest environmental impact [27]. The authors also conclude that the animal-based proteins are associate with significantly higher greenhouse gas (GHG) emissions at the production stage than plant-based proteins because: (1) emissions from feed production generally exceed those of vegetable protein farming; (2) deforestation for agriculture is dominated by feed for livestock; (3) animals create additional emissions due to enteric fermentation, manure and aquaculture ponds; (4) slaughterhouses and emissions from processing further contribute through effluents; and (5) wastage is high for fresh animal products which easily spoil [27].

On the other hand, the World Health Organisation in 2015 categorised red meat as carcinogenic to humans (Category 1 for processed meat and Category 2a for cooked meat) based on 800 studies, including 700 epidemiological studies [28]. It seems that there is a very clear and convincing picture that red meat is bad for planetary health as it negatively affects human wellbeing, mainly through its association with cancer (and colorectal cancer in particular), and for the planet through its direct impacts on land use, freshwater withdrawals, greenhouse gas emissions, including the powerful methane and nitrous oxide, acidification and eutrophication. Meat is also a major cause for biodiversity loss, increased rates of non-communicable diseases, including obesity and diabetes [29], as well as phosphorus depletion putting at risk future plant-based food production [30].

Moving from current diets to food preferences that exclude animal products has big transformative potential to deal with some of the major challenges humanity faces in these day and age. According to Poore and Nemecek [27], 
such a shift will free up 76\% of food's land use, including $19 \%$ reduction in arable land, drastically reduce greenhouse gas emissions by $49 \%$ and have many other planetary benefits. This effect will be felt differently in each country but in Australia it will be very pronounced because of the current high levels of meat consumption. However, are Australians ready to make such a shift? Through their preferences, consumers can play an important role in reducing the overexploitation of natural resources for food production and put the brakes on the global nutritional crisis [31] which leaves some hungry and undernourished and makes others overweight and obese. The relationship between food and planetary health is scientifically beyond doubt and it is time to find a new approach to individual diets which encourages the elimination or reduction in the consumption of animal-based products. To what extent people understand this and how they interpret the impacts of their diets are questions explored based on the survey in Sydney, Australia.

\section{Methodology and research sample}

Below are presented the results from an online survey conducted with Sydney residents in 2018. Sydney is a modern multicultural city which in 2017 ranked globally among the top ten most liveable cities exhibiting scenic beauty and sophisticated shops with local produce [32]. It is Australia's most populous city and the state capital of New South Wales. Its residents represent a relatively wealthy population with an estimated annual income of $\mathrm{A} \$ 80,132$ in 2016 [33]. The survey sample's income is comparable to the average for the state as a participation selection criterion was that the respondents should be employed or studying. Sydney is a good example not only for an Australian city but also for a wealthy place where there are many affordable food options from different world cuisines.

An online questionnaire was used to conduct the Sydney survey. It requested information about:

- basic demographic data - gender and age;

- frequency of meat consumption - every day, 4-6 times per week, 2-3 times per week, once per week and do not eat meat;

- any intended dietary change - no change, more plant-based products, more animal-based products, reduce meat consumption and stop eating meat;

- the main reason for meat consumption;

- level of agreement on a five-point Likert scale (ranging from Strongly Agree, Mildly Agree, Neither Agree nor Disagree to Mildly Disagree and Strongly Disagree) about three statements related to impacts of meat consumption;

- awareness about the most serious negative impacts of the current global levels of meat consumption based on six questions which required a Yes/No answer.
More explanation about the main reasons, statements and questions is provided below.

The included main possible reasons for eating meat were based on Font-i-Furnols and Gerrerro's [34] multidisciplinary model of the principal factors affecting consumer behaviour in relation to food. This model includes three groups of factors that shape people's food preferences, namely psychological, sensory and marketing. Two reasons in the survey related to psychological factors, namely: part of culture and family tradition, and meat is a symbol of strength and masculinity; one reason captured the sensory factors, namely: meat has nice taste and texture; and two reflected marketing strategies, namely: meat is healthy and nutritious; and eating meat contributes to weight loss.

A weakness of the Font-i-Furnols and Gerrerro's model [34] is that it does not explicitly identify considerations about the natural environment and climate change as contributing to consumers' food choices. This is not surprising given the fact that despite abundant scientific evidence (a detailed overview is presented in [35]), only recently has food been recognised as a significant contributor to climate change and as having multiple and multifaceted negative ecological impacts. The IPCC Special Report on the impacts of global warming of $1.5^{\circ} \mathrm{C}$ above pre-industrial levels includes four illustrative pathways for mitigating GHG emissions, all of which explicitly separate agriculture, forestry and other land use from fossil fuels and industry [36]. The first two pathways towards no or low overshoot above the $1.5^{\circ} \mathrm{C}$ goal include technological innovation to reduce $\mathrm{CO}_{2}$ without relying on carbon capture and storage but require significant reduction in agriculture-related methane emissions, namely respectively by 24 and $48 \%$, compared to 2010. Lowering the land- and GHG-intensity of food consumption is seen as important demand-side mitigation and behavioural change with one of the required system transitions being "[s]hifts in dietary choices towards foods with lower emissions and requirements for land" [36], [p. 316].

Health considerations are also not explicitly included in Font-i-Furnols and Gerrerro's [34] model although they appear to be subsumed under the sensory properties of meat. This is another weakness of the model as not all foods which have nice odour, flavour, visual appearance and in-mouth texture are healthy. Given the increasing levels of obesity and non-communicable diseases in Australia, consumers need to be specifically aware about the health implications from high levels of meat intake.

To assess the environmental and health awareness of the Sydney residents, the survey included three statements which relate to the impact of individual meat consumption on ecological, human and planetary wellbeing. 
The six questions related to negative impacts of livestock asked the opinion of the participants whether the current global levels of meat consumption impact negatively on natural resource depletion, pollution (including air, land, soil and water pollution), generation of waste, food security, other or have no impact. All questions represent environmental consequences from the increasing consumption of animal-based foods. In other words, irrespective as to whether people are concerned or not about their own individual health, the survey tried to elicit the existing level of awareness about how meat consumption affects the global commons.

The consumer behaviour model adopted in this study (see Fig. 1) expands previous research (by Font-i-Furnols and Gerrerro in [34]) by adding the environmental and health dimensions. These two dimensions are becoming increasingly important within the framework of planetary health and should form part of any policy efforts to transition to a more sustainable development.

In total, 500 randomly selected Sydney residents -250 women and 250 men, were invited to participate in the survey. The selection was done using a function to generate random numbers in Microsoft Excel from a database containing 30,000 adult women and men, Sydney residents who are either employed or in full-time study and have registered their interest to participate in surveys on a voluntary basis. Responses were received from 380 people - 139 (36.6\%) females and 241 (63.4\%) males yielding a response rate of $76 \%$. This high response rate indicates adequate interest in the issues related to meat consumption and eliminates concerns about non-respondent bias [37]. A minimum response rate of $75 \%$ is recommended as appropriate to exclude bias from those who respond or do not respond to a survey [38-40]. The survey's sample is statistically representative of Sydney's 5.6 million population with a 5.03 confidence interval width at the $95 \%$ confidence level.
Table 1 shows the age break-down of the sample compared to the total Sydney population. Our sample has a relatively good coverage comprising people between the ages of 20 and 59 with the age bracket of 30 to 49 being over-represented while the younger bracket of 20 to 29 and the older bracket of 50 to 59 being under-represented. Although we did not target statistical age representation of the Sydney residents, there is no reason to believe that the self-selection process was biased in any particular way. Sydney has a higher share of male residents $-53 \%$ males compared to $47 \%$ females within the 20 to 59 age bracket [41]. The higher share of male respondents similarly was not targeted with the survey sample; however methodologically it was important that men are not under-represented as there is a well-established correlation between meat consumption and masculinity $[42,43]$.

\section{Survey results}

The survey covered several aspects of the perceptions people have about the link between meat consumption and planetary health. We first present a general overview of the frequency of meat consumption and then investigate the reasons behind people's food choices. Then we specifically interrogate people's understanding of the two major aspects of planetary health - personal wellbeing and ecological impacts. Finally, we investigate whether people are considering changing their preferred diets and in what direction.

\section{Frequency of meat consumption}

As with Australia's general population, the majority of the Sydney participants are meat-eaters with only 20 people (5.3\%) not consuming meat (see Table 2). A further 18 (4.7\%) restrict their meat intake to only once per week. This is consistent with the Roy Morgan research which

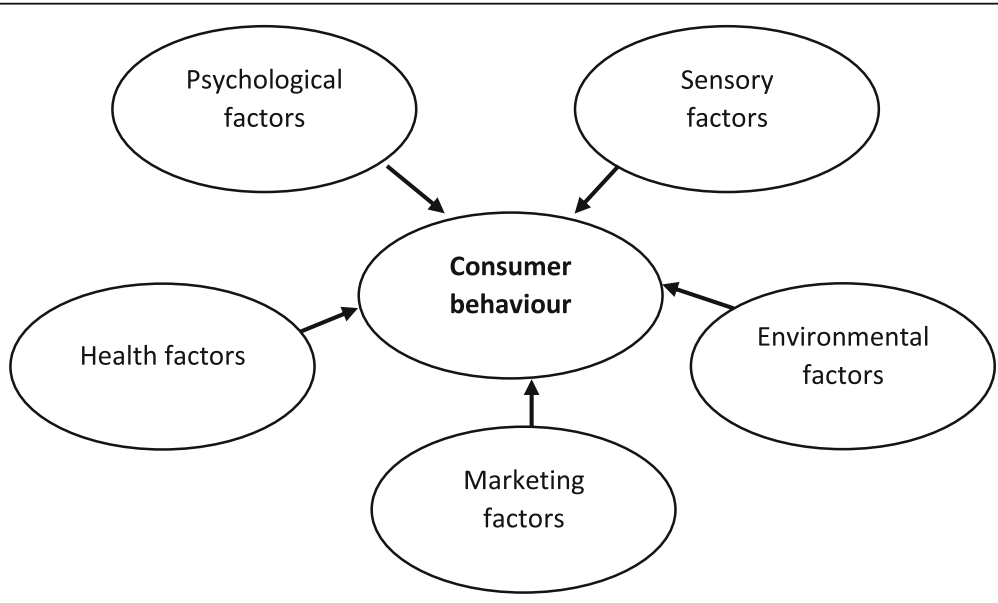

Fig. 1 Factors affecting consumer behaviour in the food domain 
Table 1 Age description of the Sydney survey sample

\begin{tabular}{llll}
\hline Age group & Number & Survey percentage & Percentage of 20 to 59 years old in Sydney population \\
\hline 20 to 29 & 101 & $26 \%$ & $42 \%$ \\
30 to 39 & 151 & $40 \%$ & $31 \%$ \\
40 to 49 & 86 & $23 \%$ & $15 \%$ \\
50 to 59 & 42 & $11 \%$ & $12 \%$ \\
Total & 380 & $100 \%$ & $100 \%$ \\
\hline
\end{tabular}

Source data: Authors and City of Sydney [41]

shows for 2016 12.4\% of the New South Wales (NSW) adult population being fully or almost vegetarian [1].

At the other end of the spectrum, meat is part of the daily diet for 137 (35.8\%) people from the Sydney sample. Lower consumption with meat being a dietary choice 2 to 3 times per week was reported by 53 (13.9\%) participants. The highest number of participants, namely 152 or $40.3 \%$, consumed meat 4 to 6 times per week which means they had some meat-free days on a regular basis.

In total, 360 or $95 \%$ of the Sydney respondents claimed to consume meat with this percentage being lower for women (92\%) than for men (96\%). These results are in line with the trends of high meat consumption in Australia, and specifically Sydney, reported previously $[43,44]$. The gender-based differences, however, are not that significant to warrant a separate attention and therefore the further reporting of the results is done for the Sydney sample in total.

Australia's strong appetite for meat has maintained consumption high since the $1960 \mathrm{~s}$ when it was $93 \mathrm{~kg}$ per person per year to reach around $110 \mathrm{~kg}$ presently [5, 45-48]. The Sydney consumers confirm this trend with the explicit preference for meat by the majority of the sample and high frequency of intake (4 and more times per week) by $76 \%$ of them.

\section{Reasons for dietary choice related to meat consumption} For Australians, the love for meat seems to be culturally entrenched and additionally fuelled by industry advertising and false beliefs [49]. It is important to reveal the discrepancies between the scientific evidence and people's attitudes to meat. One way to do this is to ask directly what are reasons behind the dietary choices made by the Sydney participants. Table 3 presents their answers. Half of the 20 people who do not eat meat do this because of their vegan or vegetarian convictions which per se represent a very complex array of reasons, including ethical and environmental. However, it is interesting to see that the other half of these people prefer to explicitly state a specific main reason, such as animal welfare (5 people), religion (2), disgust (2) and environmental concerns (1).

Overall, there is little awareness about the environmental footprint of meat with this reason receiving no recognition by the Sydney survey sample. The health side of things however is accepted but in a manner that contradicts the latest scientific evidence. It should be acknowledged that official dietary guidelines in Australia developed by its National Health and Medical Research Council have shifted from highlighting meat as an important source of iron and zinc supply in 2005 [50] to limiting the intake of red meat to $455 \mathrm{~g}$ per week and recommending eliminating processed types of meat because of human health concerns in 2013 [51]. It is surprising that five years after the publishing of the new guidelines there is still very little awareness of the risks to human health associated with regular meat consumption. In this sense, 150 people or $42 \%$ of the survey sample continue to be misinformed and eat meat for its positive nutritional value (see Table 3 ). On the other hand, this means that there has been no social marketing to influence people's perceptions whilst livestock industry advertising has continued to promote and encourage higher levels of meat consumption [52]. The perceived and unjustified health benefits of meat appear to be the prevailing reason in people's choices to consume this food. The next dominant reason for meat consumption is another perception - the connection between meat

Table 2 Frequency of meat consumption in Sydney, 2018

\begin{tabular}{lllllll}
\hline Do you eat meat? & Persons & Percentage & Men & Percentage of men & Women & Percentage of women \\
\hline No, I don't eat meat & 20 & $5.3 \%$ & 9 & $3.7 \%$ & 11 & $7.9 \%$ \\
Yes, I eat meat once per week & 18 & $4.7 \%$ & 9 & $3.7 \%$ & 9 & $6.5 \%$ \\
Yes, I eat meat 2-3 times per week & 53 & $13.9 \%$ & 33 & $13.7 \%$ & 20 & $14.4 \%$ \\
Yes, I eat meat 4-6 times per week & 152 & $40.3 \%$ & 99 & $41.1 \%$ & 53 & $38.1 \%$ \\
Yes, I eat meat every day & 137 & $35.8 \%$ & 91 & $37.8 \%$ & 46 & $33.1 \%$ \\
Total & 380 & $100 \%$ & 241 & $100 \%$ & 139 & $100 \%$ \\
\hline
\end{tabular}


Table 3 Main reason for the dietary choice related to meat consumption, Sydney, 2018

\begin{tabular}{|c|c|c|c|c|c|}
\hline Main reasons for consuming meat & Number & Percentage & Main reason for excluding meat & Number & Percentage \\
\hline Healthy and nutritious, including Iron, Zinc, B12, etc. & 150 & $42 \%$ & Vegan or vegetarian conviction & 10 & $50 \%$ \\
\hline Symbol of strength & 70 & $19 \%$ & Animal welfare & 5 & $25 \%$ \\
\hline Family traditions and part of culture & 66 & $18 \%$ & Religion & 2 & $10 \%$ \\
\hline Nice taste and texture & 65 & $18 \%$ & Disgust & 2 & $10 \%$ \\
\hline Weight loss & 7 & $2 \%$ & Environmental concerns & 1 & $5 \%$ \\
\hline Other/not stated & 2 & $1 \%$ & Other/not stated & 0 & $0 \%$ \\
\hline Total & 360 & $100 \%$ & Total & 20 & $100 \%$ \\
\hline
\end{tabular}

and strength or masculinity, with 70 respondents (or 19\%) listing this as the most influential factor in their dietary decisions. Given the negative effects of meat on planetary health, such socially constructed perception is ill-placed. A further socially constructed reason is tradition and culture with 66 participants (or 18\%) listing it as the main factor behind their meat consumption. It is interesting to observe that only 65 participants $(18 \%)$ or around 1 in 5 people eat meat mainly because they like its taste and texture. With current new plant-based meat substitutes coming on the market that imitate the feel of meat on human taste buds and have a much lighter environmental footprint, it would be difficult to justify this reason in the future [20]. A very small share of the Sydney respondents -7 people or $2 \%$ associated meat consumption with weight loss, most likely due to fad diets, such as Paleo or Atkins.

\section{Meat consumption and planetary health}

The survey participants were specifically asked to express their degree of agreement/disagreement with statements related to the link between meat consumption and planetary health. They were given statements related to ecological health and human wellbeing separately and then in combination.

Table 4 deals with the responses to the statement that meat consumption impacts negatively on the ecological health of the planet. More than a third of the participants (134 people or $35.3 \%$ ) had no opinion or were uncertain. The remaining participants were split with a much higher proportion of them - 157 (51.6\%) or more than half of the survey sample, being of the opinion that meat consumption does not negatively impact on the environment, compared to 89 (or 23.4\%) maintaining the opposite view. This means that despite the abundant scientific evidence, only less than a quarter of Sydney's population is actually aware of meat's heavy environmental impact.

Overall, 291 participants, $77 \%$ of the sample or three in four people, reported lack of adequate knowledge on the issue. This highlights the need for urgent interventions to improve people's knowledge and understanding of the seriousness of meat's environmental impact which permeates all ecological dimensions and contributes to existential threats to humanity and many other biological species.

Similar lack of knowledge is revealed in relation to the link between meat consumption and human health (see Table 5). This is not surprising given the fact that people actually report consuming meat for its health-related benefits. The share of people who are uncertain or disagree with the statement that meat consumption negatively impacts on human health is very high at 80\% (304 people) or four out of five participants. Again, interventions that improve population knowledge are required and the sooner this happens, the les burden will be expected for the health system.

There is, however, some awareness that meat consumption could be exposing humans to health risks as indicated by the remaining 76 people or $20 \%$ of the sample. This share needs to increase in order for people to have a better picture of the real situation.

To triangulate the data, we also asked the participants whether meat consumption is not impacting on both human wellbeing and the health of the planet. Not surprisingly, the majority of the respondents were not aware of a combined negative impact and agreed with this statement. The number of people who either agreed or were uncertain was 271 or $71 \%$ of the sample (see Table 6). Hence, seven out of ten people were not aware of the combined negative effect of meat consumption on planetary health.

There is however some awareness, with 109 people (or $28.7 \%$ of the sample) recognising this negative connection. In $88 \%$ of these cases however participants

Table 4 Meat consumption negatively impacts on the ecological health of the planet: 2018 Sydney responses

\begin{tabular}{lll}
\hline Level of agreement/disagreement & Number & Percentage \\
\hline Strongly agree & 33 & $8.7 \%$ \\
Mildly agree & 56 & $14.7 \%$ \\
Neither agree nor disagree & 134 & $35.3 \%$ \\
Mildly disagree & 62 & $16.3 \%$ \\
Strongly disagree & 95 & $25.0 \%$ \\
Total & 380 & $100 \%$ \\
\hline
\end{tabular}


Table 5 Meat consumption negatively impacts on human health: 2018 Sydney responses

\begin{tabular}{lll}
\hline Level of agreement/disagreement & Number & Percentage \\
\hline Strongly agree & 12 & $3.2 \%$ \\
Mildly agree & 64 & $16.8 \%$ \\
Neither agree nor disagree & 44 & $11.6 \%$ \\
Mildly disagree & 170 & $44.7 \%$ \\
Strongly disagree & 90 & $23.7 \%$ \\
Total & 380 & $100 \%$ \\
\hline
\end{tabular}

continued to consume meat, and $30 \%$ of these people do this on a daily basis (see Fig. 2). This indicates that knowledge and awareness are not enough to change people's dietary behaviour. For example, for 16 participants (or 17\%) of this group of aware people, the taste and texture of meat was the main reason for its continued consumption. If the new plant-based meat alternatives deliver similar or better sensual experiences, it is likely that these people would make a switch in their diet. A further 19 participants (or 19\%) from this group see meat as a symbol of strength. Hence, if the achievements of vegan athletes, such as Carl Lewis (sprinter), Venus Williams (tennis player), Mac Danzig (martial arts), Lewis Hamilton (Formula 1 driver), Tia Blanco (surfer), Scott Jurek (ultramarathon runner), David Haye (boxer), Heather Mills (skier), Jermain Defoe (football player), Hannah Tetter (snowboarder) and many others, are popularised, and negative consequences and health threats, such as colorectal cancer, are exposed, the myth about meat and strength is likely to be dispelled. Another 18 participants (or 19\%) from this group explained their adherence to meat because it is part of culture and family tradition. This is where social marketing has a very big role to play. Meat should no longer be part of culture in the Anthropocene, given livestock's damaging effects on planetary health and these outdated attitudes and behaviours need to change. The majority of the people from this group - 43 (or $45 \%$ ) continue to eat meat because they are still convinced that this food delivers needed nutritional benefits for the human body.

Table 6 Meat consumption does not impact on human wellbeing and the ecological health of the planet: 2018 Sydney responses

\begin{tabular}{lll}
\hline Level of agreement/disagreement & Number & Percentage \\
\hline Strongly agree & 50 & $13.2 \%$ \\
Mildly agree & 80 & $21.0 \%$ \\
Neither agree nor disagree & 141 & $37.1 \%$ \\
Mildly disagree & 78 & $20.5 \%$ \\
Strongly disagree & 31 & $8.2 \%$ \\
Total & 380 & $100 \%$ \\
\hline
\end{tabular}

Any social marketing and health advice need to stress that such and better nutritional benefits can be achieved through plant-based foods.

\section{Changing diet}

The above analysis of possible interventions to improve planetary health using reduction in meat consumption is based on how researchers see avenues for change. The survey however asked whether people themselves are planning to change their diets in the near future and in what direction.

All 20 people who currently do not eat meat do not intend to change their diet which is a positive finding. It indicates that they do not find any need to correct the sources for their nutritional intake towards consuming animal flesh. Table 7 presents the answers from the respondents who currently consume meat. More than half of them - 55\%, do not intend to make any dietary change in the near future. This means that the current trends of high meat consumption in Australia are likely to persist unless there are some deliberate interventions. Another worrying result is that $11 \%$ of the Sydney participants are actually planning to increase their meat intake. With Australia being the top meat consumer in the world, this will mean that the country's environmental impact is going to increase even further and in addition, there will be more burden on its health system. Increasing the intake of plant-based food - an intention reported by $22 \%$ of the participants, is beneficial at two levels. First, plant-based food, especially fibre from fruit, vegetables and wholegrain cereals, has an attenuating effect on the intake of red meat by reducing cancer risk [53] and therefore contributes positively on human health. Nevertheless, this does not reduce the environmental pressure associated with animal products. Secondly, a bigger intake of plant-based products may result in less consumption of meat, dairy and other animal options. As this is not always the case, efforts need to be put in place to steer consumption away from animal-based foods. The proportion of people who intend to reduce their meat consumption, including those who intend to excluding meat altogether, is $12 \%$. This is a smaller, but comparable, share than the one reported in a study representative of all Australian consumers, $18 \%$ of whom indicated having reduced their meat intake in the last 12 months [54]. Although, this percentage of meat reducers would be in addition to the people who are already not eating meat, there is no room for optimism as intentions not always translate into actions and outcomes. Also, people who have already reduced their meat intake may not continue to do so. Even if they do, this would still be a small section of the Australian population while the scale of the problem and the negative impacts on planetary health require concerted 


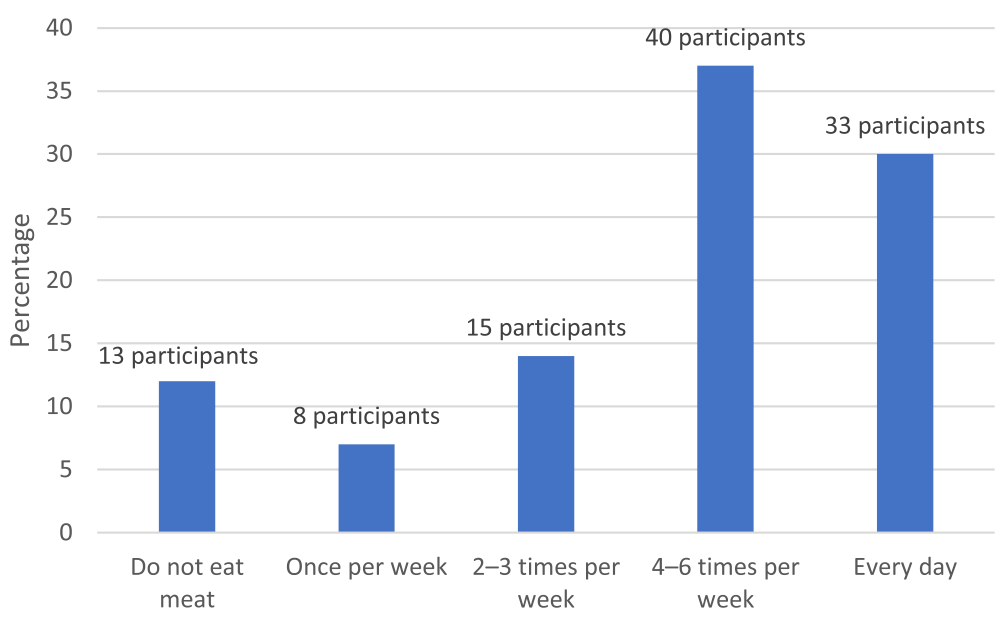

Fig. 2 Meat consumption of people who are aware of its negative impact on planetary health: 2018 Sydney responses

efforts from society as a whole - in fact, from global society. A simple call to consumers to eat less meat is likely to be met with a lot of resistance as previous research in countries, such as the Netherlands indicates [55]. In order to motivate Australian consumers about changing their diets, the message needs to combine all factors which influence consumer behaviour towards food - psychological, sensory, environmental, health and marketing (see Fig. 1) as well as offer alternatives that satisfy people's expectations. Well-developed and attractive new meat alternatives [56] can be used together with social marketing to convey the need for dietary changes and promote "health and nature-related values" [55], [p. 1].

On a positive side, the results from the Sydney survey display some transformation in future consumption behaviours, which is most likely not seriously conceptualised given the vast knowledge gaps regarding the link between meat consumption and planetary health. More action through social marketing can help speed up this process.

\section{Livestock's impact}

Finally, participants were asked for a single answer to describe livestock's most serious negative impact on a global level. The results are presented in Table 8. Quite a few, namely 74 participants (19\% of the survey sample or one in five people), were of the opinion that livestock has no negative consequences on a global scale. This can be explained by lack of knowledge, misinformation but also by the fact that most of the operations of this industry are invisible to the average Australian citizen. Australia does not have ag-gag laws as in the USA which restrict reporting of industrial agricultural practices. There are several strong non-government organisations, such as Animals Australia, which have been able to expose cruelty and inhumane treatment of animals. However, this is seen as isolated cases rather than the norm and has always been reported within an animal welfare, rather than planetary health context. Furthermore, the land conversion and clearing of native vegetation are occurring outside metropolitan areas where the majority of the Australian population lives. Being a wealthy country, Australia deals with many environmental problems related to water shortages or even greenhouse gas emissions associated with ruminant animals through technological solutions, such as desalination and investing in research to reduce natural flatulence, rather than re-consider its current practices.

As multiple answers were allowed, Table 8 shows the weighted ranking of the listed negative impacts based on 1 unit of weight per participant and 100 total weight for all answers. Concern about resource depletion, including water and land use, deforestation and depletion of

Table 7 Diet change intentions of people consuming meat: 2018 Sydney responses

\begin{tabular}{lll}
\hline Diet change & Number & Percentage \\
\hline Stop consuming meat & 4 & $1.1 \%$ \\
Reduce current meat consumption & 41 & $11.4 \%$ \\
Eat more plant-based products & 79 & $21.9 \%$ \\
Eat more animal-based food, including meat and fish & 40 & $11.1 \%$ \\
Do not intend to change my diet & 196 & $54.5 \%$ \\
Total & 360 & $100 \%$ \\
\hline
\end{tabular}


Table 8 Most serious negative impacts of current global levels of meat consumption: 2018 Sydney responses (multiple answers allowed)

\begin{tabular}{llll}
\hline$\#$ & & Number of responses & Weight \\
\hline 1 & Natural resource depletion (e.g. water, land use, deforestation, phosphorus depletion) & 107 & 28 \\
3 & Pollution (e.g. greenhouse gas emissions, water and soil contamination, antimicrobial resistance) & 86 & 55 \\
4 & Food security & 52 & 14 \\
5 & Direct waste generation & 6 & 14 \\
6 & Other (animal suffering, distribution, cost and quality of meat) & 74 & 19 \\
& There are not serious negative impacts of current global levels of meat consumption & 380 & 100 \\
\hline
\end{tabular}

phosphorus, received the highest weighting followed by pollution, including greenhouse gas emissions, water and soil contamination. Food security and direct waste generation by the livestock received less weighting but overall, $81 \%$ of the participants associated the livestock industry with some serious environmental concerns on a global scale. This poses the question as to whether Australians are not critically assessing their own contribution to these global problems and avoiding responsibility.

\section{Conclusion}

After their thorough analysis of 38,700 farms and 1600 food processing, packaging and retailing facilities, Poore and Nemecek conclude that the environmental "impacts of the lowest-impact animal products typically exceed those of vegetable substitutes" [27] [p. 987] and appeal for the most needed dietary changes. The Sydney study, however, shows that only $10 \%$ of the city's residents are currently opting for predominantly plant-based diets by excluding meat completely or having it no more than once per week. Even the $25 \%$ of people aware about the negative impact meat consumption has on planetary health continue to eat animal-based products. Although some people intend to make a shift in their diets towards reducing meat intake, their numbers are not high enough to trigger a fast change in the current system. Furthermore, Australians seem to avoid taking responsibility for their own contribution to the deterioration of planetary health as despite the fact that $81 \%$ of the survey participants appear to be aware of the global negative impacts of livestock, Australia as a country continues to have the highest meat consumption per capita in the world.

Against this background, urgent changes are needed to transform Australian diets. The study is the first to explain these changes from the perspective of planetary health. Based on the Sydney evidence, it makes a strong case for interventions by changing the marketing of meat. Social marketing has a role to play in this process to create local awareness and dispel some myths and long-held beliefs about meat consumption. Planetary health is the union between human wellbeing and that of all other species on this planet. High meat consumption is not part of this union. The scientific evidence about the negative impact of animal-based foods on planetary health is abundant and conclusive [57]; however, it seems that it is yet to reach ordinary Australians as well as policy makers who need to press for and use social marketing to ignite a new wave of attitudes and behavioural changes. A transition to diets based predominantly on plant options, including new meat analogues, can bring hope for a better life on this planet.

\section{Abbreviations}

\%: Percent; A\$: Australian dollar; e.g.: For example (from Latin: exempli gratia); FAO: Food and Agriculture Organisation of the United Nations; GHG: Greenhouse gas; kg: Kilogram; p.: Page; SDGs: Sustainable Development Goals; UN: The United Nations; USA: The United States of America

\section{Acknowledgements}

The authors acknowledge the contribution of an Australian Government Research Training Program Scholarship in supporting this research. They are also thankful for the financial support received by the Burning Questions Initiative supported by Rachel's Network which commemorates and expands the work of Rachel Carson.

\section{Funding}

Burning Questions Initiative supported by Rachel's Network

Availability of data and materials

Please contact the corresponding author for data requests.

Authors' contribution

DM and DB designed the study, analysed the data and wrote the paper; DB collected the survey data. Both authors read and approved the final manuscript.

Ethics approval and consent to participate

An ethics approval was obtained from the Curtin University Human Research Ethics Committee (approval number RDHU-82-15).

Consent for publication

Not applicable.

Competing interests

The authors declare that they have no competing interests.

\section{Publisher's Note}

Springer Nature remains neutral with regard to jurisdictional claims in published maps and institutional affiliations. 
Received: 11 June 2018 Accepted: 6 March 2019

Published online: 13 March 2019

\section{References}

1. Roy Morgan. The slow but steady rise of vegetarianism in Australia. 2016. http://www.roymorgan.com/findings/vegetarianisms-slow-but-steady-rise-inaustralia-201608151105. Accessed 11 Jun 2018.

2. Department of Agriculture and Water Resources. Agricultural commodities: March quarter 2017. http://www.agriculture.gov.au/abares/publications/ display?url=http://143.188.17.20/anrdl/DAFFService/display.php?fid=pb_ agcomd9abcc20170307 0S6mp.xml. Accessed 11 Jun 2018.

3. Ritchie H, Roser M. Meat and Seafood Production \& Consumption. Our World in Data. 2017; https://ourworldindata.org/meat-and-seafoodproduction-consumption. Accessed 11 Jun 2018.

4. Marinova D, Raphaely T. Taxing meat and animal food products. In: Bogueva D, Marinova D, Raphaely T, editors. Handbook of research on social marketing and its influence on animal origin food product consumption. Hershey: IGI Global; 2018. p. 121-34

5. Taylor E, Butt A. Three charts on: Australia's declining taste for beef and growing appetite for chicken. The Conversation. 2017; https:// theconversation.com/three-charts-on-australias-declining-taste-for-beef-andgrowing-appetite-for-chicken-78100. Accessed 11 Jun 2018

6. Marsh K, Saunders A, Zeuschner C. Red meat and health: evidence regarding red meat, health, and chronic disease risk. In: Raphaely $T$ Marinova D, editors. Impact of meat consumption on health and environmental sustainability. Hershey: PA IGI Global; 2016. p. 131-77.

7. Marsh K, Saunders A, Zeuschner C. The health impact of eating foods of animal origin: evidence regarding animal foods, health, and disease risk. In: Bogueva D, Marinova D, Raphaely T, editors. Handbook of research on social marketing and its influence on animal origin food product consumption. Hershey: IGI Global; 2018. p. 17-36.

8. Horton R, Beaglehole R, Bonita R, Raeburn J, McKee M, Wall S, et al. From public to planetary health: a manifesto. Lancet. 2014;382(9920):847.

9. Whitmee S, Haines A, Beyrer C, Boltz F, Capon AG, de Souza Dias BF, et al. Safeguarding human health in the Anthropocene epoch: report of the Rockefeller Foundation-lancet commission on planetary health. Lancet. 2015;386(10007):1973-2028.

10. United Nations Development Programme (UNDP) Sustainable Development Goals. 2017. http://www.undp.org/content/undp/en/home/sustainabledevelopment-goals.html. Accessed 11 Jun 2018.

11. Horton R, Lo S. Planetary health: a new science for exceptional action. Lancet. 2017:386(10007):1921-2.

12. Crutzen PJ, Stoermer EF. The Anthropocene. Global Change Newsletters. 2000;41:17-8.

13. Crutzen PJ. Geology of mankind: the Anthropocene. Nature. 2002;415:23.

14. Samson PR, Pitt DC. The biosphere and noosphere reader: global environment, society, and change. London: Routledge; 1999.

15. Weart SR. The discovery of global warming. Cambridge: Harvard Press; 2003.

16. Meadows DH, Meadows DL, Randers J, Behrens III WW. The limits to growth: a report for the Club of Rome's project on the predicament of mankind. New York: Universe Books; 1972.

17. Casassus B. Obituary per Fugelli. Lancet. 2017:390(10107):2032.

18. Brondizio ES, O'Brien K, Bai X, Biermann F, Steffen W, Berkhout F, et al. Reconceptualizing the Anthropocene: a call for collaboration. Glob Environ Chang. 2016:39:318-27.

19. Dasgupta P, Ehrlich PR. Pervasive externalities at the population, consumption, and environment nexus. Science. 2013;340:324-8.

20. Schmidinger K, Bogueva D, Marinova D. New meat without livestock. In: Bogueva D, Marinova D, Raphaely T, editors. Handbook of research on social marketing and its influence on animal origin food product consumption. Hershey: IGI Global; 2018. p. 344-61.

21. Australia: OECD countries. SDG Index and Dashboards Report. 2018. https:// dashboards.sdgindex.org/\#/AUS. Accessed 8 Mar 2019.

22. Osofsky S. Explaining planetary health. One Health @ Cornell. 2016; https:// blogs.cornell.edu/onehealth/2016/11/20/explaining-planetary-health/. Accessed 11 Jun 2018

23. Myers SS, Gaffikin L, Golden CD, Ostfeld RS, Redford KH, Ricketts TH, et al. Human health impact of ecosystem alteration. PNAS. 2013;110(47): 18753-60.

24. Cook J, Oreskes N, Doran PT, Anderegg WRL, Verheggen B, Maibach EW, et al. Consensus on consensus: a synthesys of consensus estimates on human-caused global warming. Environ Res Lett. 2016;11(4):048002 http:// www.iopscience.iop.org/article/10.1088/1748-9326/11/4/048002. Accessed 11 Jun 2018.

25. Intergovernmental Panel on Climate Change (IPCC). Climate Change 2014 Synthesis report. Fifth Assessment Report 2014. https://ar5-syr.ipcc.ch. Accessed 23 Dec 2018.

26. Marinova D, Raphaely T. Impact of vegetarian diets on the environment. In: Craig W, editor. Vegetarian nutrition and wellness. Boca Raton: CRC Press; 2018. p. 13-24.

27. Poore J, Nemecek T. Reducing food's environmental impacts through producers and consumers. Science. 2018:360:987-92.

28. World Health Organisation. Q\&A on the carcinogenicity of the consumption of red meat and processed meat. 2015. http://www.who.int/features/qa/ cancer-red-meat/en/. Accessed 11 Jun 2018.

29. Raphaely T, Marinova D, editors. Impact of meat consumption on health and environmental sustainability. Hershey: IGI Global; 2016.

30. White S, Cordell D. Global phosphorus security - diet, sustainability and food for thought. In: Soeters K, editor. Meat the future: how cutting meat consumption can feed billions more. Amsterdam: Nicholaas G. Pierson Foundation; 2015. p. 75-86.

31. Global Panel on Agriculture and Food Systems for Nutrition (GLOPAN) Food systems and diets: facing the challenges of the 21 st century. London: GOPLAN; 2016. http://glopan.org/sites/default/files/ForesightReport.pdf. Accessed 11 Jun 2018.

32. These are the 20 greatest cities to live in. The Telegraph. https://www. telegraph.co.uk/travel/galleries/The-worlds-most-liveable-cities/sydney/. Accessed 11 Jun 2018.

33. Average salary Australia. Living in Australia. https://www.livingin-australia. com/salaries-australia/. Accessed 11 Jun 2018.

34. Font-i-Furnols M, Gerrerro L. Consumer preference, behavior and perception about meat and meat products: an overview. Meat Sci. 2014;98(3):361-71.

35. Tirado R, Thompson KF, Miller KA, Johnston P. Less is more: Reducing meat and dairy for a healthier life and planet. Greenpeace Research Laboratories Technical Report (Review) 03-2018. 2018. https://storage.googleapis.com/ planet4-international-stateless/2018/03/6942c0e6-longer-scientificbackground.pdf. Accessed 23 Dec 2018.

36. Intergovernmental Panel on Climate Change (IPCC). Global Warming of $1.5^{\circ} \mathrm{C}$. Special Report. 2018. https://www.ipcc.ch/sr15/. Accessed 23 Dec 2018.

37. Dillman DA. Introduction to tailored design. In: Dillman DA, editor. Mail and internet surveys: the tailored design method. New York: Wiley; 2000. p. 3-31.

38. Babbie ER. Survey research methods. Belmont: Wadsworth; 1990.

39. Fowler FJ. Survey research methods. 2nd ed. Thousand Oaks: Sage; 1993.

40. Ary D, Jacobs L, Razavieh A. Introduction to research in education. Fort Worth: Holt, Rinehart, and Winston; 1996.

41. City of Sydney. Population and age structure. id community demographic resources. https://forecast.id.com.au/sydney/population-age-structure. Accessed 11 Jun 2018.

42. Adams CJ, Calarco M. Derrida and the sexual politics of meat. In: Potts A, editor. Meat culture. Leiden: Brill; 2016. p. 31-53.

43. Bogueva D, Marinova D. What is more important perception of masculinity or personal health and the environment? In: Bogueva D, Marinova D, Raphaely T, editors. Handbook of research on social marketing and its influence on animal origin food product consumption. Hershey, PA: IGI Global; 2018. p. 148-62.

44. Bogueva D, Marinova D, Raphaely T. Reducing meat consumption: the case for social marketing. Asia Pac J Mark Logist. 2017;29(3):477-500.

45. Ting I. Australia is the meat eating capital of the world. Sydney Morning Herald. 2015; https://www.smh.com.au/healthcare/australia-is-the-meateatingcapital-of-the-world-20151027-gkjhp4.html. Accessed 11 Jun 2018.

46. Wong L, Selvanathan EA, Selvanathan S. Modelling the meat consumption patterns in Australia. Econ Model. 2015;49:1-10 https://doi.org/10.1016/j. econmod.2015.03.002

47. Organisation for Economic Cooperation and Development. Meat consumption (indicator)/. OECD Data. 2016. https://doi.org/10.1787/ fa290fd0-en. https://www.oecd-ilibrary.org/agriculture-and-food/meatconsumption/indicator/english_fa290fd0-en. Accessed 8 Mar 2019.

48. Evans M. Do we eat too much meat? SBS. 2017. https://www.sbs.com.au/ food/article/2016/10/13/do-we-eat-too-much-meat. Accessed 11 Jun 2018.

49. Bogueva D, Phau I. Meat myths and marketing. In: Raphaely T, Marinova D, editors. Impact of meat consumption on health and environmental sustainability. Hershey: PA IGI Global; 2016. p. 264-76. 
50. National Health and Medical Research Council (NHMRC). Food for health. 2005. http://www.hnehealth.nsw.gov.au/hneph/Nutrition/Documents/foodfor-health.pdf. Accessed 8 Mar 2019.

51. National Health and Medical Research Council (NHMRC). Australian Dietary Guidelines. Canberra, Australia: NHMRC. 2013. https://nhmrc.gov.au/aboutus/publications/australian-dietary-quidelines. Accessed 8 Mar 2019.

52. Bogueva D, Marinova D, Raphaely T, editors. Handbook of research on social marketing and its influence on animal origin food product consumption. Hershey: IGI Global; 2018.

53. Williamson CS, Foster RK, Stanner SA, Buttriss JL. Red meat in the diet. Nutr Bull. 2005;30:323-55 https://doi.org/10.1111/j.1467-3010.2005.00525.x. Accessed 11 Jun 2018

54. Maleka L, Umberger W, Goddard E. Is anti-consumption driving meat consumption changes in Australia? Br Food J. 2018. https://doi.org/10.1 108/ BFJ-03-2018-0183.

55. de Boer J, Schösler H, Boersema JJ. Climate change and meat eating: an inconvenient couple? J Environ Psychol. 2013;33(March):1-8.

56. Bogueva D, Marinova D, Raphaely T, Schmidinger K, editors. Environmental, health and business opportunities in the new meat alternatives market. Hershey: IGI Global; 2019.

57. Springmann M, Clark M, Mason-D'Croz D, Wiebe K, Bodirsky BL, Lassaletta L, de Vries W, Vermeulen SJ, Herrero M, Carlson KM, Jonell M, Troell M, Declerck F, Gordon L, Zurayk R, Scarborough P, Rayner M, Loken B, Fanzo J, Godfray HCJ, Tilman D, Johan Rockström J, Willett W. Options for keeping the food system within environmental limits. Nature. 2018;165(4184):519-42.

Ready to submit your research? Choose BMC and benefit from:

- fast, convenient online submission

- thorough peer review by experienced researchers in your field

- rapid publication on acceptance

- support for research data, including large and complex data types

- gold Open Access which fosters wider collaboration and increased citations

- maximum visibility for your research: over $100 \mathrm{M}$ website views per year

At BMC, research is always in progress.

Learn more biomedcentral.com/submissions 